\title{
Dental Bleaching with 35 and $38 \%$ Hydrogen Peroxide and Immersion in Soft Drink: Analysis by Reflectance and Fourier Transform- Raman Spectroscopy
}

\author{
${ }^{1}$ Gustavo de Luca Alves, ${ }^{1}$ Raffaela Di lorio Jeronymo, ${ }^{2}$ Eduardo Galera da Silva, ${ }^{3}$ Maria Filomena Rocha
} Lima Huhtala, ${ }^{3}$ Carlos Rocha Gomes Torres, ${ }^{4}$ Egberto Munin, ${ }^{5}$ Ana Paula Martins Gomes

${ }^{1}$ Postgraduate Student, Department of Restorative Dentistry, São José dos Campos Dental School, UNESP, São Paulo State University São José dos Campos, São Paulo, Brazil

${ }^{2}$ Assistant Professor, Department of Social and Pediatric Dentistry, São José dos Campos Dental School, UNESP, São Paulo State University São José dos Campos, São Paulo, Brazil

${ }^{3}$ Assistant Professor, Department of Restorative Dentistry, São José dos Campos Dental School, UNESP, São Paulo State University São José dos Campos, São Paulo, Brazil

${ }^{4}$ Assistant Professor, Department of Restorative Dentistry, Camilo Castelo Branco University, São Paulo, Brazil

${ }^{5}$ Associate Professor, Department of Restorative Dentistry, São José dos Campos Dental School, UNESP, São Paulo State University São José dos Campos, São Paulo, Brazil

Correspondence: Raffaela Di lorio Jeronymo, Postgraduate Student, Department of Restorative Dentistry, Faculdade de Odontologia de São José dos Campos, UNESP, A Francisco José Longo, 777, São José dos Campos, SP, CEP: $12245-000$ Brazil, Phone: 55 (12) 3947-9048, e-mail: raffadi@ig.com.br

\section{ABSTRACT}

Objective: The aim of this study was to evaluate the effects of dental bleaching with 35 and $38 \%$ hydrogen peroxide and soft drink immersion on the chemistry and color of the bovine enamel fragments before and after treatment using reflectance and Fourier transform-Raman spectroscopy (FT-Raman spectroscopy).

Materials and methods: Sixty bovine enamel fragments were prepared and randomly divided into six experimental groups according to the hydrogen peroxide gel concentration or immersion in soft drink $(n=10)$ : G1-Whiteness HP Maxx; G2-Whiteness HP Maxx + light lemon coke immersion; G3-Opalescence Xtra Boost; G4-Opalescence Xtra Boost + light lemon coke immersion; G5-Whiteform Perox Red Form gel; G6-Whiteform Perox Red Form gel + light lemon coke immersion. The bleaching treatment was performed in two sessions with a 7 days interval and the analysis before treatments were used as control (baseline). Samples were submitted to reflectance and FT-Raman spectroscopy analysis to evaluate surface mineral content and the reflectance before and after treatments.

Results: There was no significant statistical difference among the bleaching agents in the reflectance analysis $(p=0.63)$. The FT-Raman spectroscopy data showed significant loss in enamel mineral content after immersion in the light lemon coke and statistical significant differences for the interactions between 'bleaching agent' and 'immersion in soft drink' $(p=0.03)$ and between 'bleaching agent' and 'time' $(p=0.04)$. With regards to the whitened specimens, the Opalescence Xtra Boost agent demonstrated the greatest loss in enamel mineral content.

Conclusion: All bleaching agents exhibited great bleaching potential in reflectance analysis. This highly concentrated hydrogen peroxide gel $(38 \%)$ changed significantly the enamel mineral content with or without immersion in soft drink. The specimens immersed in soft drink showed significant loss in enamel mineral content.

Clinical relevance: Some investigations have shown that hydrogen peroxide and beverages can modify enamel dental components, but more studies are necessary to explain its effects.

Keywords: Dental bleaching, Bovine enamel, Hydrogen peroxide, Light reflectance, FT-Raman spectroscopy.

\section{INTRODUCTION}

In the last decades, the esthetics issue has become an essential requirement of patients as the functionality with a significant relevance for dental practice. Changes in smiling have shown an amazing impact on peoples self-esteem. ${ }^{1}$ Dental esthetics has been an important factor for patients who are looking for procedures which can recover their smile through a less invasive approach.

Dental bleaching has currently become more popular and has been well accepted by the society due to the importance given to dental esthetics. This procedure has been indicated for teeth discolored by trauma, endodontic procedures, aging, ingestion of colored beverages and foods, tobacco and for those ones which became naturally discolored. This procedure can be done for both vital and nonvital teeth., ${ }^{2,3}$

Nowadays, bleaching products can be found as a gel in different concentrations of carbamide peroxide or hydrogen peroxide, depending on the application method used. ${ }^{4}$

The etiology of tooth staining can be considered as a multifactorial issue. Most authors classify it as extrinsic (in enamel 
surface) and intrinsic (incorporated into tooth matrix). Although extrinsic staining can be removed by dental prophylaxis, intrinsic staining requires chemical whitening methods. ${ }^{4-6}$

The bleaching process occurs due to the release of free radicals, which chemically interact with the pigment molecules that are present in hard teeth tissues and become smaller. ${ }^{7}$ Hydrogen peroxide $\left(\mathrm{H}_{2} \mathrm{O}_{2}\right)$ is a powerful oxidizing agent and it is known as one of the most efficient bleaching agents. Bleaching mechanisms involve extracellular matrix degradation and chromophors oxidation, which can be found in enamel and dentin. ${ }^{8}$

Hydrogen peroxide can promote several degrees of porosity in the surface, structural alterations and permeability. Coffee, tea, juices, wine and cola-based soft drink are solutions which can stain enamel surface. Some of them are acidic and lead to an increase in demineralization. Dental professionals do not recommend the ingestion of beverages and use of tobacco, especially after the $35 \%$ hydrogen peroxide use, once that studies state that enamel's surface alterations can be caused by bleaching products. ${ }^{9,10}$

Nowadays, professionals and patients have the chance to choose a variety of bleaching agents. Nevertheless, they have limited information about their effects. The demanding process for new techniques and bleaching material require specialized knowledge, with regards to their effects on tissues, including the most safety application technique. ${ }^{11}$ Therefore, the objective of this study was to evaluate the effects of dental bleaching with 35 and 38\% hydrogen peroxide and soft drink immersion on the chemistry and color of the bovine enamel before and after treatment using reflectance and FT-Raman spectroscopy.

\section{MATERIALS AND METHODS}

\section{Sample Preparation}

Sixty bovine incisors teeth, from the same age and lot were used in this experiment. After extraction, all teeth were stored in distilled water until the cleaning process could be performed. Following the disinfection procedure $(0.1 \%$ tymol for $24 \mathrm{~h})$, all teeth were manually scaled with a periodontal curette and sodium bicarbonate jet, and rinsed with distilled water, in order to remove organic residues. The samples were submitted to stereomicroscopy (4×) (Stemi 2000-C - Carl Zeiss Jena), so that any type of fracture lines and cracking could be verified; those could certainly affect the results of this investigation. The teeth were maintained in closed containers with distilled water at a temperature of $15^{\circ} \mathrm{C}$ (Brastemp - Whirlpool S/A, São Paulo, SP, Brazil) until further use.

The crown was separated from the root using a diamond disk attached to a low speed manual cutting machine (LABCUT 1010, EXTEC Corp). Proximal faces (mesial and distal), incisal and cervical were discharged and a flat and regular surface could be obtained. The crowns were sectioned in four parts to obtain a cube shape. Proximal and lingual faces were ground under water cooling, by means of 600 grit silicon carbide sandpaper and \#1200 aluminum oxide, which were both attached to a sanding machine (DP10 -Panambra, Brazil). Small fragments (4 mm long $\times 4 \mathrm{~mm}$ wide $\times 4 \mathrm{~mm}$ thick) were obtained and verified by using a digital Vernier caliper (Digimess, Brasil Hobby, Rio de Janeiro, Brazil). Vestibular enamel remained intact. All specimens were stored in distilled water and maintained in culture kiln at $37^{\circ} \mathrm{C}$ before the bleaching procedures. Afterward, they were individually stored in a container with $2 \mathrm{ml}$ of artificial saliva (Byofórmula, Farmácia de Manipulação, São José dos Campos, SP, Brazil), also at $37^{\circ} \mathrm{C}$. The saliva sample was replaced each 24 hour.

\section{Specimens' Immersion in Soft Drink}

The enamel surface was previously covered with a double face adhesive tape (3M, Campinas, SP, Brazil) and the exposed surfaces (mesial, distal and lingual) were coated with two layers of colorless nail varnish (Revlon Inc. New York, NY, USA). The staining process of G2, G4 and G6 was performed by immersion of the specimens in light lemon coke ${ }^{\circledR}$ (Coca-Cola, $350 \mathrm{ml}$ ). The nail varnish was applied on the surface twice, but the second application was performed 24 hour after the first one, in order to have a complete drying of the first layer. The adhesive tape was removed and the vestibular face was cleaned with humid gauze.

After these procedures, the specimens were submitted to the staining process by being immersed in $2 \mathrm{ml}$ of light lemon coke. The specimens were maintained, immersed in the solution for 10 minutes through a period of 10 days. All samples were rinsed in water for 10 seconds immediately after their removal from the solution, and were placed back into the $2 \mathrm{ml}$ artificial saliva container.

\section{Bleaching Protocol}

For bleaching protocol, the bovine enamel fragments were randomly divided into six experimental groups $(\mathrm{n}=10)$ according to chart 1 . The bleaching agents were used according to the manufacturer's instructions. The bleaching gel was applied as a $0.5 \mathrm{ml}$ thick layer, by means of the glass hypodermic syringe, on the enamel surface of each fragment. The gel was light activated for 30 seconds using a LED/LASER Ultrablue System (DMC, São Carlos, SP, Brazil) and the total bleaching time was 10 minutes of application for each specimen.

The gel was removed by suction and the specimens were rinsed with distilled water. The gel application was repeated twice more. All fragments were then rinsed in distilled water and stored in $2 \mathrm{ml}$ artificial saliva at $37^{\circ} \mathrm{C}$ for 7 days, and the first reading was collected. Artificial saliva was changed daily. One more application was performed and the specimens were stored for second reading of the bleaching process (14 days after bleaching).

\section{Reflectance Analysis}

The bovine dental blocks were analyzed using a reflectance spectroscopy to evaluate changes in enamel photoreflectance. 
Dental Bleaching with 35 and 38\% Hydrogen Peroxide and Immersion in Soft Drink: Analysis by Reflectance

\begin{tabular}{|c|c|c|c|c|c|}
\hline Groups & Products & Bleaching agent & Composition & $\mathrm{pH}$ value & $\begin{array}{l}\text { Immersion in soft } \\
\text { drink }\end{array}$ \\
\hline G1 & $\begin{array}{l}\text { Whiteness HP Maxx } \\
\text { (FGM, Joinville, SC, } \\
\text { Brazil) }\end{array}$ & $\begin{array}{l}35 \% \text { hydrogen } \\
\text { peroxide }\end{array}$ & $\begin{array}{l}\text { Distilled water, } \\
\text { carbopol, glycol, } \\
\text { potassium ions }\end{array}$ & $6.0-7.0$ & Without immersion \\
\hline G2 & $\begin{array}{l}\text { Whiteness HP Maxx } \\
\text { (FGM, Joinville, SC, } \\
\text { Brazil) }\end{array}$ & $\begin{array}{l}35 \% \text { hydrogen } \\
\text { peroxide }\end{array}$ & $\begin{array}{l}\text { Distilled water, } \\
\text { carbopol, glycol, } \\
\text { potassium ions }\end{array}$ & $6.0-7.0$ & Light lemon coke \\
\hline G3 & $\begin{array}{l}\text { Opalescence Xtra Boost } \\
\text { (Ultradent, South Jordan, } \\
\text { Utah, USA) }\end{array}$ & $\begin{array}{l}38 \% \text { hydrogen } \\
\text { peroxide }\end{array}$ & No information & 4.5 & Without immersion \\
\hline G4 & $\begin{array}{l}\text { Opalescence Xtra Boost } \\
\text { (Ultradent, South Jordan, } \\
\text { Utah, USA) }\end{array}$ & $\begin{array}{l}38 \% \text { hydrogen } \\
\text { peroxide }\end{array}$ & No information & 4.5 & Light lemon coke \\
\hline G5 & $\begin{array}{l}\text { Whiteform-Perox Red } \\
\text { Form Gel (Fórmula and Ação, } \\
\text { São Paulo, SP, Brazil) }\end{array}$ & $\begin{array}{l}35 \% \text { hydrogen } \\
\text { peroxide }\end{array}$ & No information & $3.0-5.0$ & Without immersion \\
\hline G6 & $\begin{array}{l}\text { Whiteform-Perox Red } \\
\text { Form Gel (Fórmula and Ação, } \\
\text { São Paulo, SP, Brazil) }\end{array}$ & $\begin{array}{l}35 \% \text { hydrogen } \\
\text { peroxide }\end{array}$ & No information & $3.0-5.0$ & Light lemon coke \\
\hline
\end{tabular}

Enamel sample spectra were obtained before and after the bleaching procedure.

The samples were previously placed in a reflectance system for the first reading, which was nominated as the experimental control group (baseline). The analysis system was compound of a spectrometer (Model 77702, Oriel Instruments, Stratford, CT), a Teflon integrating sphere, a halogen light (Model 150 Illuminator, Ram Optical Instrumentation, Chicago, IL) as the source of white light, two optical fibers and a computer. The halogen light was attached to the optical fiber - $600 \mu$ m diameter (Fiberguide Ind. - Superguide G fiber SFS 600/660T) and each sample received light inside the integrating sphere at a distance of $3 \mathrm{~mm}$. The white light power measured at the edge of the fiber was $4 \mathrm{~mW}$. The radiation that spread through the sample was captured by an optical fiber of $600 \mu \mathrm{m}$ diameter, which was attached to a spectrometer and data transferred to the computer for plotting the graphs.

Before the spectrum capture, the system was calibrated with regards to the wavelength measurement. This was carried out by irradiating a beam of red-yellow (632.8 and 594 nm respectively). He-Ne laser associated with mercury lamp (435.8, 546.1, 576.9 and $579 \mathrm{~nm}$ ). In order to minimize errors coming from any instability of the equipment, the background signal, as well as the reference signal coming from the standard sample (Teflon), was captured each 10 minutes before the measurements.

The signals were evaluated in the Microcal Origin 6.0 software (Microcal Software, Inc. Northampton, MA). The spectral curve and the area under the curve were observed.

\section{Fourier Transform Raman Spectroscopy (FT-Raman Spectroscopy)}

Spectra of all specimens, before (baseline) and after enamel treatments (bleaching or control), were obtained using an
FT-Raman Spectrometer RFS100 (Bruker Optics Inc. Karlsruhe, Germany). To excite the spectra, the defocused $1064.1 \mathrm{~nm}$ line of a Nd:YAG laser source was used. Maximum incident laser power on the surface of the specimens was about $100 \mathrm{~mW}$ and spectrum resolution was $4 \mathrm{~cm}^{-1}$. For each sample, one spectrum was collected at a central point on the enamel surface. In order to obtain a good signal to noise ratio, 100 scans were coadded for each spectra.

The spectra in the region of interest, from 300 to $4000 \mathrm{~cm}^{-1}$, were analyzed using a curve-fitting routine, which allowed the subtraction of background scattering and reduction of noise level by digital filtering. All spectra were processed by fitting eight Raman vibrational stretching modes: phosphate (430, 451, 587, $615 \mathrm{~cm}^{-1}$ ) and carbonate (1030, 1044, 1070 and $1102 \mathrm{~cm}^{-1}$ ).

Following the plotting of the spectrum, the removal of the fluorescence and the correction of the baseline were achieved by using the Microcal Origin 6.0 software for each measurement. Subsequently, the important band related to the C-H bond was evaluated with a Raman displacement in $2933 \mathrm{~cm}^{-1}$. The relative area of this band was calculated by the Microcal Origin 6.0 software. The band fitting of characteristic peaks was performed using a combined Gaussian/Lorentzian function to determine the exact position, peak intensities and areas. The behavior of the enamel was observed for each bleaching agent and for the coke-based soft drink.

\section{Statistical Analysis}

Data were submitted to statistical analysis using ANOVA (twoway) and Tukey's test. Data were analyzed to evaluate differences between periods before and after bleaching treatment. The level of significance adopted was 5\%. For all bleaching agents, an additional analysis was performed using 
ANOVA and Dunnett's test for the time after immersion and before the treatment.

\section{RESULTS}

\section{Reflectance Spectra Results}

The mean values ( \pm standard deviation) verified for the reflectance spectra analysis are shown in Table 1 . The increase in the reflectance value demonstrates the whitening process of the specimens.

The effect of the factors 'bleaching agent', 'immersion in soft drink' and 'time' was separately evaluated and the interaction among them also by means of the analysis of variance. The results of the analysis of variance showed statistical significance for the interaction between the 'immersion in soft drink' and 'time' factors ( $p=0.0005)$. However, the other interactions were not statistically significant
( $p>0.05)$. No statistical difference was verified for the 'bleaching agent' factor ( $\mathrm{p}=0.63)$.

The significant interaction ('immersion in soft drink' $\times$ 'time') was verified by means of the Tukey's test (Table 2). The reflectance of the bleaching agents was significant greater after the bleaching treatment. After the bleaching process, the groups demonstrated similar reflectance.

The Dunnett's test was carried out in order to compare the data verified for the postimmersion period and the others for each bleaching agent (Table 3 ). The reflectance analysis demonstrated that the specimens were significant darker after immersion period for all bleaching agents.

\section{FT-Raman Spectra Results}

The mean values ( \pm standard deviation), verified for the FT-Raman spectra analysis, are shown in Table 4.

Table 1: Reflectance mean values ( \pm standard deviation) verified for the groups before and after bleaching treatment

\begin{tabular}{|c|c|c|c|}
\hline \multirow[t]{2}{*}{ Bleaching agent } & \multicolumn{3}{|c|}{ Time } \\
\hline & Before bleaching & $\begin{array}{l}\text { After immersion } \\
\text { in soft drink }\end{array}$ & After bleaching \\
\hline $\operatorname{Maxx}$ & $\begin{array}{l}\text { (G1) } 17576.26(876.28) \\
\text { (G2) } 18528.53(642.37)\end{array}$ & $\begin{array}{l}\text { No immersion } \\
17105.36(573.40)\end{array}$ & $\begin{array}{l}20585.46(825.91) \\
19448.21(962.68)\end{array}$ \\
\hline Op & $\begin{array}{l}\text { (G3) } 17433.61(875.13) \\
\text { (G4) } 18228.47(1019.83)\end{array}$ & $\begin{array}{l}\text { No immersion } \\
16708.50(470.77)\end{array}$ & $\begin{array}{l}20350.42(658.77) \\
20418.05(811.78)\end{array}$ \\
\hline $\mathrm{Fa}$ & $\begin{array}{l}\text { (G5) } 17833.66(776.38) \\
\text { (G6) } 18305.33(533.76)\end{array}$ & $\begin{array}{l}\text { No immersion } \\
168366.80 \text { (532.42) }\end{array}$ & $\begin{array}{l}19964.71(314.080) \\
19830.53(606.82)\end{array}$ \\
\hline
\end{tabular}

Maxx: Whiteness HP Maxx (FGM, Joinville, SC, Brazil); Op: Opalescence Xtra Boost (Ultradent, South Jordan, Utah, USA); Fa: Whiteform Perox Red Form Gel (Fórmula \& Ação, São Paulo, SP, Brazil)

Table 2: Reflectance mean values ( \pm standard deviation) verified for the groups in function of 'immersion in soft drink' and 'time' factors. Data for bleaching agents were grouped

\begin{tabular}{llr} 
Immersion in & \multicolumn{2}{c}{ Time } \\
\cline { 2 - 3 } soft drink & Before bleaching & After bleaching \\
Without immersion & $17614.51(831.60) \mathrm{Bb}$ & $20300.19(666.88) \mathrm{Aa}$ \\
With immersion & $18374.11(742.72) \mathrm{Ab}$ & $19898.93(878.06) \mathrm{Aa}$
\end{tabular}

Mean values followed by different letters show statistical significant difference in Tukey's test $(p<0.005)($ small letters show the comparison between the time period in each immersion and capital letters show the comparison of immersion in each time period). Coefficient of variation: $4.53 \%$

\begin{tabular}{|c|c|c|c|}
\hline \multirow[t]{2}{*}{ Bleaching agent } & \multicolumn{3}{|c|}{ Time } \\
\hline & Initial & After immersion in soft drink & After bleaching procedures \\
\hline $\operatorname{Maxx}$ & $18528.53(642.37)^{*}$ & $17105.36(573.40)$ & $19448.21(962.68)^{*}$ \\
\hline Op & $18228.47(1019.83)^{*}$ & $16708.53(470.77)$ & $20418.05(811.78)^{*}$ \\
\hline $\mathrm{Fa}$ & $18305.33(533.76)^{*}$ & $168366.80(532.42)$ & $19830.53(606.82)^{*}$ \\
\hline
\end{tabular}

*Mean values for different significant periods after the immersion treatment (ANOVA and Dunnett's test, $p<0.0001$ ) 
Table 4: FT-Raman spectra $\left(\mathrm{cm}^{-1}\right)$ mean values ( \pm standard deviation) verified for the groups before and after bleaching treatment

\begin{tabular}{clll}
\multicolumn{3}{c}{ Bleaching agent } & \multicolumn{2}{c}{ Time } \\
\cline { 2 - 4 } Maxx & Before bleaching & After immersion in soft drink & After bleaching \\
Op & (G1) $6.51(0.85)$ & No immersion & $6.37(0.58)$ \\
& (G2) $5.69(0.27)$ & $5.78(0.40)$ & $5.91(0.28)$ \\
Fa & (G3) $5.85(0.36)$ & No immersion & $5.68(0.47)$ \\
& (G4) $5.99(0.58)$ & $5.59(0.49)$ & $5.81(0.60)$ \\
& (G5) $6.04(0.32)$ & No immersion & $6.32(0.60)$ \\
& (G6) $6.00(0.37)$ & $5.82(0.33)$ & $6.20(0.52)$
\end{tabular}

Maxx: Whiteness HP Maxx (FGM, Joinville, SC, Brazil); Op: Opalescence Xtra Boost (Ultradent, South Jordan, Utah, USA); Fa: Whiteform Perox Red Form Gel (Fórmula \& Ação, São Paulo, SP, Brazil)

Table 5: Mean values ( \pm standard deviation) for Raman $\left(\mathrm{cm}^{-1}\right)$ displacement in function of bleaching agent and immersion in soft drink. All data were grouped for each time period

\begin{tabular}{ccc} 
Bleaching agent & \multicolumn{2}{c}{ Immersion } \\
\cline { 2 - 3 } & No & Yes \\
Maxx & $6.44(0.72) \mathrm{Aa}$ & $5.80(0.29) \mathrm{Ab}$ \\
Op & $5.76(0.42) \mathrm{Ba}$ & $5.90(0.58) \mathrm{Ba}$ \\
Fa & $6.18(0.49) \mathrm{Aa}$ & $6.10(0.45) \mathrm{Aa}$
\end{tabular}

Mean values followed by different letters show statistical significant difference in Tukey's test $(p<0.05)$ (small letters show the comparison between the immersion for each bleaching agent and capital letters show the comparison of bleaching agents in each immersion). Coefficient of variation: $5.63 \%$

Table 6: Mean values ( \pm standard deviation) for Raman $\left(\mathrm{cm}^{-1}\right)$ displacement in function of bleaching agent and time. All immersion data were grouped for each time period

\begin{tabular}{lcc} 
Bleaching agent & \multicolumn{2}{c}{ Time } \\
\cline { 2 - 3 } & Initial & Final \\
Maxx & $6.10(0.75) \mathrm{Aa}$ & $6.14(0.50) \mathrm{Aa}$ \\
Op & $5.92(0.47) \mathrm{Aa}$ & $5.72(0.53) \mathrm{Bb}$ \\
$\mathrm{Fa}$ & $6.02(0.34) \mathrm{Aa}$ & $6.26(0.55) \mathrm{Aa}$
\end{tabular}

Mean values followed by different letters show statistical significant difference in Tukey's test $(p<0.05)$ (small letters show the comparison between the time period in each bleaching agent and capital letters show the comparison of bleaching agents in each time period). Coefficient of variation: $5.63 \%$

The analysis of variance evaluated the effect of factors, 'bleaching agent', 'immersion in soft drink'and 'time', separately and also the interaction among them.

The results showed statistical significance for the interactions between the 'bleaching agent' and 'immersion in soft drink' $(p=0.03)$ and 'bleaching agent' and 'time' $(p=0.04)$. The other interactions were not statistically significant $(p>0.05)$. Significant differences between interactions ('bleaching agents' $\mathrm{x}$ 'immersion in soft drink' and 'bleaching agents' $\times$ 'time') were verified by using the Tukey's test (Tables 5 and 6 ).

The Raman $\left(\mathrm{cm}^{-1}\right)$ displacement value of the Maxx bleaching agent was significantly greater for the group without immersion in soft drink. When compared with the other agent, the Maxx bleaching agent showed smaller Raman displacement
Table 7: Mean values ( \pm standard deviation) for Raman $\left(\mathrm{cm}^{-1}\right)$ displacement for the immersed groups in the three experimental periods

\begin{tabular}{llll} 
Bleaching agent & \multicolumn{3}{c}{ Time } \\
\cline { 2 - 4 } & & $\begin{array}{l}\text { After } \\
\text { immersion } \\
\text { in soft drink }\end{array}$ & $\begin{array}{l}\text { After } \\
\text { bleaching }\end{array}$ \\
Maxx & $5.59(0.27)$ & $5.78(0.40)$ & $5.91(0.28)$ \\
Op & $5.99(0.58)$ & $5.59(0.49)$ & $5.81(0.60)$ \\
Fa & $6.00(0.37)$ & $5.82(0.33)$ & $6.20(0.52)$
\end{tabular}

Mean values for period time which were not significantly different from the postimmersion period (ANOVA and Dunnett's test, $p>0.05$ )

after immersion. The other bleaching agents did not show differences among both groups, immersed and nonimmersed, in soft drink. The Op bleaching agent showed the smallest Raman $\left(\mathrm{cm}^{-1}\right)$ displacement compared with the other agents when immersed or not in soft drink.

The Raman $\left(\mathrm{cm}^{-1}\right)$ displacement value for the Op bleaching agent was significantly smaller after bleaching period. No difference was observed for the other bleaching agents between the initial and final periods. The groups demonstrated similar Raman $\left(\mathrm{cm}^{-1}\right)$ displacement value in the initial period. After bleaching treatment, the Op group showed the smallest mean value.

The Dunnett's test was further performed to compare the postimmersion period data with the other periods for each bleaching agent (Table 7). The postimmersion period did not show any difference when compared to the others for all bleaching agents.

\section{DISCUSSION}

The bleaching agents have been represented by the peroxide groups, which can be subdivided into hydrogen and carbamide in different concentrations, and release hydrogen peroxide as the bleaching agent, which is certainly related to the technique chosen: Home bleaching or office bleaching technique. ${ }^{12}$ These agents have low molecular weight, which lead to a greater diffusion through teeth tissues. ${ }^{13}$

Before bleaching treatment, the specimens were evaluated and the initial values for reflectance and FT-Raman spectroscopy were recorded. The values were used as control group (baseline) for all experimental groups. ${ }^{14-16}$ The statistical 
analysis between initial and postbleaching periods showed high reflectance values for the experimental groups, which were not submitted to the staining process (Table 1). In this study, there was no statistical significant difference with regards to bleaching agents when the reflectance analysis was performed.

Changes in color are not the only resultants of dental bleaching. Data from the mineral composition analysis for the groups, which were not submitted to the staining process and were bleaching with the Whiteness HP Maxx, Opalescence Xtra Boost and Whiteform Perox Red Form Gel, showed that the Opalescence Xtra Boost agent had significant smaller values with regards to the Raman $\left(\mathrm{cm}^{-1}\right)$ displacement. These results demonstrate loss in mineral content after bleaching protocol. Concerning the other agents, there was no significant difference between the initial and final periods. Therefore, the greatest loss in mineral content can be related to the composition of the bleaching agents, the presence of a catalyst which promotes the chemical reaction, and also due to the nonlight activation process. Another factor that could have affected the results was the higher concentration of hydrogen peroxide, such as 38\%. The others tested bleaching agents have a 35\% hydrogen peroxide and must be light activated.

Several studies are in accordance to these results found in relation to the loss in mineral content. ${ }^{15-20}$ Nevertheless, Park et $\mathrm{al}^{14}$ verified that there was no difference in bovine enamel composition, when bleached or not, after 30\% hydrogen peroxide treatment. Jiang et $\mathrm{al}^{21}$ did not find any alteration in enamel composition; however, it is important to mention that the $30 \%$ hydrogen peroxide was associated to hydroxyapatite. Duschner et $\mathrm{al}^{15}$ and Gotz et $\mathrm{al}^{25}$ evaluated the action of hydrogen peroxide bleaching strips, 6.0 and 6.5\%, 11.7 and $14 \%$ concentration, respectively, in the chemical composition of human enamel, by means of the FT-Raman spectroscopy and verified that there was no significant structural changes after dental bleaching. Though, it is important to mention that the specimens were stored in saline solution and distilled water, factors that might have affected the results, once that in our study the artificial saliva maintained at $37^{\circ} \mathrm{C}$ was used as a storing solution.

Light lemon coke was used in this study for the staining procedures due to its high consumption by people and also the association to lemon juice. Sales-Peres et $\mathrm{al}^{22}$ evaluated the different $\mathrm{pH}$ values of soda and verified that Coke ${ }^{\circledR}$ and Light Coke ${ }^{\circledR} \mathrm{pH}$ showed the lowest values for his experimental groups, 2.9 and 3.2, respectively. Hence, the contact between those substances and dental enamel can lead to loss in mineral content. White et $\mathrm{al}^{23}$ showed that enamel demineralization starts when in contact to beverages at $\mathrm{pH}$ values lower or equal to 6 .

The results of the statistical analysis showed greater reflectance values for the application of bleaching agents on stained specimens. With regards to the chemical composition of bovine enamel, it could be verified that the Opalescence Xtra Boost showed the smallest value for the FT-Raman displacement analysis, which represents alterations in phosphate and carbonate, for both experimental levels tested, with and without immersion in soft drink. The other bleaching agents (Whiteness HP Maxx and Whiteform Perox Red Form Gel) did not show significant statistical differences when compared to the Opalescence Xtra Boost. The greatest reduction in phosphate and carbonate levels can be related to its chemical composition, not described by the manufacturer. It can be verified that the light cured activation is not necessary due to a nonspecified catalyst, which can certainly increase and accelerate the chemical reaction. Yet, there is difference in composition, as the concentration of hydrogen peroxide is $38 \%$. Price et $\mathrm{al}^{24}$ evaluated the $\mathrm{pH}$ of several bleaching products and observed that the most acidic $\mathrm{pH}$ was found for the 35\% Opalescence bleaching agent, which suggests a more acidic $\mathrm{pH}$ for the 38\% Opalescence Xtra Boost gel. Therefore, the greater loss in mineral content would be justified.

The results found are not in accordance with the studies proposed by Park et al, ${ }^{14}$ Duschner et $\mathrm{al}^{15}$ and Gotz et al. ${ }^{25} \mathrm{~A}$ different chemical reaction might have occurred and affected the results obtained. The technique used for the dental bleaching was proposed by the manufacturer, which used high concentration of peroxides. In the current study, 35 and 38\% hydrogen peroxide was used for different brands. Manufacturer's instructions were followed for all bleaching agents, which were different for each protocol used. Similar studies ${ }^{19,26}$ are in accordance with the results found in this study, which verified that bleaching agents available in the market have shown efficacy in whiten both stained or nonstained teeth. However, office bleaching requires some precautions because it can produce structural and enamel composition alterations. Thus, it is essential to follow the correct instructions of the manufacturer during and after the dental bleaching period.

\section{CONCLUSION}

All bleaching agents exhibited great bleaching potential in reflectance analysis. This highly concentrated hydrogen peroxide gel (38\%) significantly changed the enamel mineral content with or without immersion in soft drink. The specimens immersed in soft drink showed significant loss in enamel mineral content.

\section{REFERENCES}

1. Akarslan ZZ, Sadik B, Erten H, Karabulut E. Dental esthetic satisfaction, received and desired dental treatments for improvement of esthetics. Indian J Dent Res Apr-June 2009;20(2):195-200.

2. Camargo SE, Valera MC, Camargo CH, Gasparoto Mancini MN, Menezes MM. Penetration of 38\% hydrogen peroxide into the pulp chamber in bovine and human teeth submitted to office bleach technique. J Endod Sep 2007;33(9):1074-77.

3. Camargo SE, Cardoso PE, Valera MC, de Araujo MA, Kojima AN. Penetration of $35 \%$ hydrogen peroxide into the pulp chamber in bovine teeth after LED or Nd:YAG laser activation. Eur J Esthet Dent 2009 Spring;4(1):82-88.

4. Benbachir N, Ardu S, Krejci I. Spectrophotometric evaluation of the efficacy of a new in-office bleaching technique. Quintessence Int Apr 2008;39(4):299-306. 
5. Sulieman M. An overview of tooth discoloration: Extrinsic, intrinsic and internalized stains. Dent Update Oct 2005;32(8): 463-64, 446-68, 471.

6. Kwon YH, Huo MS, Kim KH, Kim SK, Kim YJ. Effects of hydrogen peroxide on the light reflectance and morphology of bovine enamel. J Oral Rehabil 2002;29:471-77.

7. Braun A, Jepsen S, Krause F. Spectrophotometric and visual evaluation of vital tooth bleaching employing different carbamide peroxide concentrations. Dent Mater Feb 2007;23(2):165-69.

8. Goldberg M, Grootveld M, Lynch E. Undesirable and adverse effects of tooth-whitening products: A review. Clin Oral Investig Feb 2010;14(1):1-10.

9. Berger SB, Coelho AS, Oliveira VAP, Cavalli V, Giannini M. Enamel susceptibility to red wine staining after $35 \%$ hydrogen peroxide bleaching. J Appl Oral Sci May-June 2008;16(3): 201-04.

10. Azrak B, Callaway A, Kurth P, Willershausen B. Influence of bleaching agents on surface roughness of sound or eroded dental enamel specimens. J Compilation 2010;22(6):391-99.

11. Mielczarek A, Klukowska M, Ganowicz M, Kwiatkowska A, Kwasny $\mathrm{M}$. The effect of strip, tray and office peroxide bleaching systems on enamel surfaces in vitro. Dent Mater Nov 2008;24(11):1495-500.

12. Burrows S. A review of the safety of tooth bleaching. Dent Update Dec 2009;36(10):604-6, 608-10, 612-14.

13. Joiner A. The bleaching of teeth: A review of the literature. J Dent Aug 2006;34(7):412-19.

14. Park HJ, Kwon TY, Nam SH, Kim HJ, Kim KH, Kim YJ. Changes in bovine enamel after treatment with a 30\% hydrogen peroxide bleaching agent. Dent Mater J Dec 2004;23(4): 517-21.

15. Duschner H, Gotz H, White DJ, Kozak KM, Zoladz JR. Effects of hydrogen peroxide bleaching strips on tooth surface color, surface microhardness, surface and subsurface ultrastructure, and microchemical (Raman spectroscopic) composition. J Clin Dent 2006;17(3):72-78.

16. Cesar ICR, Soares LES, Alves LP, Martin AA, Munin E, Liporoni PCS. Fourier Transform-Raman and reflectance studies on dental enamel bleached with hydrogen peroxide activated using a light-emitting diode-laser system. Photomed Laser Surg. 2009;27(6):1-7.

17. Attin $\mathrm{T}$, Schmidlin PR, Wegehaupt F, Wiegand A. Influence of study design on the impact of bleaching agents on dental enamel microhardness: A review. Dent Mater Feb 2009;25(2):143-57.

18. Hosoya N, Honda K, Iino F, Arai T. Changes in enamel surface roughness and adhesion of Streptococcus mutans to enamel after vital bleaching. J Dent Nov 2003;31(8):543-48.

19. Ito Y, Momoi Y. Bleaching using $30 \%$ hydrogen peroxide and sodium hydrogen carbonate. Dental Mater J 2011;30(2): 193-98.

20. Paula SS, Soares LES, Espirito Santo AM, Martin AA, Cavalli V, Liporoni PCS. FT-Raman and energy dispersive X-ray fluorescence spectrometric analyses of enamel submitted to $38 \%$ hydrogen peroxide bleaching, an acidic beverage and simulated brushing. Photomed Laser Surg June 2010;28(3):391-96.

21. Jiang $\mathrm{T}$, Ma X, Wang $\mathrm{Y}$, Tong $\mathrm{H}$, Shen $\mathrm{X}, \mathrm{Hu} \mathrm{Y}$, et al. Investigation of the effects of $30 \%$ hydrogen peroxide on human tooth enamel by Raman scattering and laser-induced fluorescence. J Biomed Opt Jan-Feb 2008;13(1):014019.

22. Sales-Peres SHC, Magalhães AC, Machado MAAM, Buzalaf MAR. Evaluation of the erosive potential of soft drinks. Eur J Dent Jan 2007;1(1):10-13.

23. White AJ, Yorath C, Ten Hengel V, Leary SD, Huysmans MC, Barbour ME. Human and bovine enamel erosion under 'singledrink’ conditions. Eur J Oral Sci Dec 2010;118(6):604-09.

24. Price RB, Sedarous M, Hiltz GS. The $\mathrm{pH}$ of tooth-whitening products. J Can Dent Assoc Sep 2000;66(8):421-26.

25. Gotz H, Duschner H, White DJ, Klukowska MA. Effects of elevated hydrogen peroxide 'strip' bleaching on surface and subsurface enamel including subsurface histomorphology, microchemical composition and fluorescence changes. J Dent June 2007;35(6):457-66.

26. Lima DANL, Aguiar FHB, Liporoni PCS, Munin E, Ambrosano GMB, Lovadino JR. In vitro evaluation of the effectiveness of bleaching agents activated by different light sources. J Prosthodont Apr 2009;18(3):249-54. 